occurrence; as is also the absence of any sac. The case also gces to show how reticent some women are in confiding all their tronbles to the medical attendant; and also how some will attempt to diagnose and take the treatment of their condition into their own hands.

Whittlesey.

\section{Olinital âdos:}

MEDICAL, SURGICAL, OBSTETRICAL, AND THERAPEUTICAL.

\section{A CASE OF RECURRENT ILEO-CECAL INTUS-} SUSOEPTION ; OPERATION ; RECOVERY.

By J. D. Fiddes, M.A., B Sc., M.B., Ch.B. A Berd., LATE RESIDENT MEDICAL OFFICER, ROYAL HOSPITAL FOR SICK CHILDREN, ABERDEEN.

THE patient, a boy, aged 3 years, was admitted to the Royal Hospital for Sick Children, Aberdeen, at 11 A.M. on Feb. 24th, 1911. He had become acutely ill on the same morning at 5 o'clock. The condition on admission was as follows. Temperature $98^{\circ} \mathrm{F}$. ; pulse 120 . The child looked very ill, and every few minutes brought up a green bilious vomit. There were very evident spasms of severe colicky pains coming on every three minutes, during which he cried and drew up his legs. The bowels had moved the day before admission, when the stool was green and foul-smelling. The child was now passing only clear mucus by the rectum. No blood had been seen. The abdomen was soft and easily palpable. The patient was very quiet between the spasms of colic. A distinct sausage-shaped tumour was discovered at the outer edge of the right rectus just below the liver. No abnormality was felt per rectum.

The mother stated that for the last 18 months the child had been troubled with constipation, and had several acute attacks of colicky pains, but that medical advice had not been sought, except on two of these occasions when the pain had been more severe. Dr. Laura S. Sandeman had been called in, who kindly informed me that the first of these occasions was about ten months previous to the present attack when the case was diagnosed as one of intussusception, a distinct tumour being felt on the right side of the abdomen. There was at that time vomiting, but no blood was passed by the rectum. The medical attendant arranged im mediately for the child to go into hospital, but on returning to see him previous to removal found that all the symptoms had disappeared. The attack lasted 24 hours. The second severe attack was about three months before admission, and was somewhat similar to the first. On this occasion the child again had vomiting of a bilious character, but, in addition, had passed blood per rectum. The attack lasted only from three to four hours. There had been two or three minor attacks between these two severe ones.

On admission the child was at once taken into the operating theatre and Mr. H. M. W. Gray opened the abdominal cavity by a paracentral incision, retracting the right rectus muscle outwards. There was found to be a wellmarked ileo-cæcal intussusception, about 2 inches in length. The ileum about 8 inches from the ileo-cæcal junction was seen to be bound down by adhesions to the upper and back part of the pelvis for the extent of about $2 \frac{1}{2}$ inches. The appendix was partially embedded in these adhesions and was 6 inches long, club-shaped, and showed distinct signs of chronic inflammation. The intussusception was reduced easily. The adhesions joining the ileum to the pelvis were then divided and the raw area left was covered by transplanted omentum which was fixed in position by a few interrupted iodine catgut sutures. The appendix was removed and the abdomen closed. Fither, given by the open method, was administered by Dr. A. Ogston.

The recovery of the patient was nneventful. There was no post-operative vomiting and no special post-operative treatment was adopted. The bowels moved naturally 24 hours after operation, and in 56 hours the child was on ordinary hospital diet and looking exceedingly well. The skin sutures were removed on the fourth day and the boy left hospital on the tenth day after operation.
The interest of the above case lies in the fact of the lack of any very severe symptoms, the comparatively small extent of the intussusception, and of the spontaneous cure of the previous attacks, all of which were, without doubt, due to the presence of the adhesions between the lower part of the ileum and the pelvis, which prevented more than the "slack" of the ileum from entering the intussusception. The child has remained in perfectly normal health since the operation.

I am indebted to Mr. Gray, surgeon to the hospital, for permission to publish tbis case.

Sheffield.

\section{NOTE ON A TOXIO EFFEOT OF ASPIRIN.}

By Alexander Brown, M.B. Lond., M.R.C.S. ExG.,

$$
\text { L. R.C.P. LOND. }
$$

AspIRIN is frequently taken by persons without medical advice, and a toxic symptom which I believe must be fairly common, though little commented upon, is therefore worth noting.

Several years ago I was called at night to see a man to whom I had that day prescribed tabloids (10 grain doses) of aspirin for rheumatic fibrositis of the shoulder muscles. I found him pacing his bedroom in a state of great alarm and presenting an extraordinary appearance. His face was bloated so as to be hardly recognisable, the lips were immensely swollen, the palpebral fissures were closed owing to cedema of the lids, the tongne was so enlarged that it could not be protruded, and he was unable to articulate. Large dusky wheals of urticaria covered the thorax and arms. The condition had developed suddenly. After some hours, during which I remained with him, giving him ice to suck and sips of cold strong infusion of tea, the condition subsided sufficiently to enable me to see his fauces, which were œdematous and dusky. All medication was stopped, and by next day the patient had recovered. I suspected the aspirin, but he himself ascribed the condition to food poisoning. At a later date, in order to test the accuracy of my opinion, I prescribed one tablet (5 gr.) of aspirin. This was followed by urticaria of the arms which lasted for a day.

A secord experience of the kind has occurred in my practice. A young woman gave the following history. She had returned from business on a Saturday afternoon with a headache and had lain down for a few hours, and had then risen and dressed to go to an entertainment, but at the railway station she suddenly felt her lips, jaws, and tongue to enlarge, and she returned home in great alarm. Her mother stated that her face was almost unrecognisable, being covered with a swollen rash. When I saw her, an hour and a half later, there was nothing whatever to see except one or two faint blotches on the arms. I put the question, "Have you been taking any tablets?" "Yes," was the answer ; "but only two aspirins for my head." The diagnosis was clear.

It is interesting to think whether such toxic effect is due to impurities in the drug, or whether it may be idiosyncrasy. Probably it is the latter, for though in the first case mentioned above the drug was probably pure, in the latter case there was not the same guarantee with the tablet. Nevertheless, the young woman remembered on three previous occasions to bave taken aspirin without such result. And even if the toxic effect be due to impurity it is quite likely that idiosyncrasy must still be called in to explain the occasional poisoning which occurs among the bundreds of people who take the undoubtedly large number of impure specimens of the drug on the market.

Bartholomew-road, N.W.

\section{NOTE ON A CASE OF TORSION OF THR TESTICLE,}

\section{By Wilfrio AtTlee, M.D. CaNtab., M.R.C.S. Eng, L.R.C.P. LOND.}

ASSISTANT PHYSICIAN, KING EDWARD YII. HOSPITAL, WINDSOR:

THE following incident may prove of interest to the readers of THE LANCET.

A boy at school, aged 16 $\frac{1}{2}$ years, was kicking a football about, and felt some pain in the right testicle. He took little notice of it, and came in when he had finished his game, had his bath, and ate his tea. The pain continued, however, and increased, and he began to feel faint and L 3 
vomited twice. I examined him about three hours after the first symptoms; he was lying on a couch looking white and faint, and evidently in considerable pain. The right side of the scrotum looked larger than the left, and the right testicle was drawn up towards the external ring. Palpation caused pain, but it was easy to make out that the external ring contained no hernia, that the right cord felt thick and hard, and that the right epididymis was in front of the testis, and lying towards the middle line. It seemed evident that the testis was twisted upon its cord, and probable, from the history, that the twist was in the direction of the hands of a clock, if one looked upwards towards the patient's head. Manipulation proved that this deduction was correct, for after turning the testis back through about a right angle the epididymis rotated with a jerk back to its normal position, and the pain immediately disappeared. Ten minutes later the boy had regained his colour and felt perfectly well. He has had no symptoms since.

The boy tells me that he had a blow on the right testicle some year or two ago, and he thinks this testicle has been a little smaller than the other since then. The right testis is certainly a little smaller than the left at the present time, but except for this there is nothing abnormal about it. It would be interesting to know why a testicle should stick in such a position, and whether such a condition would have righted itself if left alone, or gone on to strangulation and pssibly to gangrene. At any rate, the apparent rarity of the occurrence seems sufficient justification for recording it. Eton.

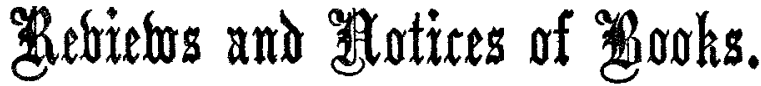

A Treatise on Diagnostic Methods of Examination. Bg Professor Dr. HERMANN SAHLI, Director of the Medical Clinic, University of Bern. Edited, with additions, by Nathaniel Bowditch PotTer, M.D, Assistant Professor of Clinical Medicine at Columbia University (College of Physicians and Surgeons), New York. Second edition, revised. Authorised translation from the fifth revised and enlarged German edition. London and Philadelphia: W. B. Saunders Company. 1911. Pp. 1229. Price 27s. 6a. net.

Professor Sahli's book on diagnostic methods is so well known and has attained such an established position as a standard work of reference that any detailed review of its contents, even if such were possible within small limits, i3 unnecessary. We may therefore confine ourselves to a brief notice of its scope and general character, with mention of s Jme of the new matter included in this, the second English, edition.

The term "diagnostic" methods is taken to comprise any procedure which is calculated to afford information in regard to the diagnosis of a patient's condition. Consequently it includes physical methods, as well as the laboratory and instrumental investigations which are now so various and of such wide application. The descriptions given are always practical and sufficiently detailed to enable the process under consideration to be carried out. Although many alternative methods may be described, Professor Sahli invariably states which, in his opinion, is the most reliable. His book is no mere collection of methods copied from other works or from special monographs, but a carefully digested presentation of his own experience. It is this personal note which gives the special character to the book, and renders it one to which reference may be made for practical assistance in working out the nature of difficult cases. It also contains a number of ariginal observations upon many matters which have not taeen published elsewhere.

In connexion with the nature of fever Professor Sabli rejects the commonly accepted view that it is due to a disturbance of heat regulation, and suggests that it is essentially a circulatory disturbance by which blood is diverted from the skin to the deeper organs, with the results that heat dissipation is lessened and the febrile rise of temperature brought about. He believes in the existence of "latent fever"-i.e., a febrile disturbance of the circulation without rise of temperature. He also maintains that fever is purposeful, and that the altered circulatory conditions act beneficially by bringing more blood to the damaged viscera. The raised temperature is, in his view, a by-effect, and not necessarily beneficial. Some interesting observations upon dyspncea are directed to showing that this is strikingly adapted to the particular respiratory obstruction causing it. Some tracings by Hofbauer showing graphically various types of respiration are included.

The newer methods of investigation of the circulatory system are examined at some length, and copious illustrations of the instruments used and of the tracings obtained by them are given. Professor Sabli, however, urges cantion in the interpretation of small waves upon the venous tracing, especially in conditions of irregularity. It is remarkable that no mention of electro-cardiographic methods is made in this connexion. In referring with approval to Bäumler's work upon arterio-sclerosis, it is maintained that this condition is often diagnosed upon insufficient grounds and that arterio-sclerotic changes are frequently very unevenly distributed, so that thickening of a superficial artery is not sufficient evidence of general arterio-sclerosis. The chapter on percussion contains a full discussion of the explanation of the percussion note and of its modifications.

The methods of examination of the stomach and intestines are desoribed at great length. In particular the analysis of the gastric contents and the use of various test meals, with the information obtainable from them, are exhaustively dealt with. Professor Sthli's own methods, including the desmoid and glutoid tests, and the butyrometric process for examination of the gastric functions, are fully discussed and defended against the criticisms to which they have been subjected. The sections dealing with the examination of the urine, sputum, and blood are brought fully up to date. Professor Sahli brings forward a suggestion that pernicious anæmia is a consequence of diminished hydrochloric acid in the gastric juice, with a resulting diminution in the absorption of iron. He reviews the main facts of the disease in the light of this theory. He minimises the importance of hæmoIytic processes in this disease, but his arguments do not seem to us to carry conviction. The question of exploratory punctures is fully discussed, and the new work upon the cytology and chemistry of the fluids obtained is included. The examination of the nervous system is discussed systematically and is as exhaustive as the other sections of the book. The subject of aphasia is considered in detail, and the recent views of $P$. Marie are criticised adversely.

The book is copiously illustrated by diagrams, plates, and photographic reproductions. The translation has been well done, and the editor has contributed numerous notes. Many of the illustrations of cases have apparently been added by him, as they are derived from American sources. We can recommend this book as a valuable work of reference.

Lehrbuch der Magen- und Darmkrankheiten mit besonderer Beriïoksiohtigung der Diätet2sohen und Medikamentösen Therapie. (Text-book of Diseases of the Stomaoh and Intestines, with Speoial Consideration of Dietetio and Medioinal Treatment) Für praktische Aerzte und Studierende. Bearbeitet von Dr. P. RoDARI, Privatdozent an der Universität, Zürich. Zweite völlig umgearbeitete und bedeutend erweiterte Auflage. (Second fully revised and enlarged edition.) Wiesbaden: J. F. Bergmann. 1910. Pp. 521. Price 12 marks, or 12s.

THE clinical investigation of diseases of the digestive organs has been enriched by numerous methods of examination which have rendered diagnosis and treatment of these conditions much more rational and exact than was formerly 